\title{
Cervical disc degeneration and neck pain
}

This article was published in the following Dove Press journal: Journal of Pain Research

\author{
Baogan Peng' \\ Michael J DePalma² \\ 'Department of Spinal Surgery, \\ General Hospital of Armed Police \\ Force, Beijing 100039, People's \\ Republic of China; ${ }^{2}$ Interventional \\ Spine and Musculoskeletal Care, \\ Virginia iSpine Physicians, PC \\ Virginia Spine Research Institute, Inc \\ Richmond, VA, USA
}

\begin{abstract}
Cervical intervertebral disc has long been considered a common source of neck pain. However, the pain caused by the disc itself has not been clearly defined so far, and its diagnosis and treatment has always been controversial. Degenerative cervical disc has a rich supply of nerve fibers, is prone to inflammatory reactions, and is susceptible to pain that can be provoked by disc stimulation or distention, and can be eliminated by block. Overwhelming clinical evidence demonstrates that neck pain in patients with degenerative cervical radiculopathy or myelopathy can be subsided rapidly by anterior cervical surgery, further indicating that this neck pain stems from the pathology of cervical disc itself. Cervical discography is advocated as the only test that connects disease to symptoms, but the procedure remains controversial. If strict criteria and technique are maintained, discography can discriminate painful, symptomatic discs from nonpainful, asymptomatic discs. Discogenic neck pain alone without cervical disc herniation or cervical spondylosis accounts for a large proportion of chronic neck pain. For these patients who continue to have refractory neck pain and fail to respond to conservative treatment, anterior cervical fusion surgery or artificial cervical disc replacement may be a better choice, and preoperative cervical discography can guarantee the excellent surgical results. Existing basic and clinical studies have scientifically shown that cervical intervertebral disc degeneration can lead to neck pain.
\end{abstract}

Keywords: cervical intervertebral disc, chronic neck pain, discogenic neck pain, disc degeneration, anterior cervical surgery, cervical discography

\section{Introduction}

Neck pain is a significant public health problem worldwide. ${ }^{1,2}$ Cervical intervertebral disc has long been considered a common source of neck pain..$^{3-7}$ Although it has always been there, there has been no clear definition of pain from the disc itself, and its diagnosis and treatment has been highly controversial. ${ }^{8,9}$ The main factors contributing to this ambiguity may be deficient of understanding of its pathogenesis and lack careful observation and thorough reflection on some clinical studies. In a review of the causes of neck pain, Evans ${ }^{10}$ wrote "Although possible, there is no strong evidence that intervertebral discs (through degenerative or other changes) are a source of pain (discogenic pain). This area remains controversial". A systematic review and guidelines from the Bone and Joint 2000-2010 task force on neck pain insisted that "there is no evidence (that was deemed scientifically admissible) demonstrating that disc degeneration is a risk factor for neck pain". ${ }^{11}$ So, what is the truth? Is the degenerative cervical disc a source of neck pain? Can existing basic and clinical studies give an accurate answer scientifically?
Correspondence: Baogan Peng

Department of Spinal Surgery, Institute of Spinal Surgery, General Hospital of Armed Police Force, 69 Yongding Road, Beijing 100039, People's Republic of China

Tel +86 I0 57976611

Fax +86 I0 57976937

Email pengbaogan@163.com 


\section{Innervation of cervical intervertebral disc}

One systematic review estimated neck pain mean point, annual, and lifetime prevalence rates of $7.6 \%$ (range $5.9 \%-22.2 \%$ ), 37.2\% (range $16.7 \%-75.1 \%$ ), and $48.5 \%$ (range 14.2\%-71\%), respectively. ${ }^{1}$ Neck pain in the absence of radiculopathy, myelopathy, or clear serious underlying disease is also called mechanical neck pain. Despite the frequency of this presenting complaint, a clear understanding of its etiology is often elusive, until diagnostic procedures are completed. ${ }^{12}$

Any innervated neck structures, such as muscles, synovial joints, intervertebral discs, dura mater, and ligaments, may cause pain theoretically. Cloward ${ }^{3}$ stimulated cervical discs mechanically and electrically to verify that the evoked pain originated in the discs themselves, rather than from irritation of adjacent structures. Annular tears stimulated within symptomatic cervical discs support the concept that the evoked index neck pain originates from the discs. ${ }^{13,14}$ Cloward $^{3}$ also proposed that disc pain is mediated through sinuvertebral nerves. Subsequent anatomical studies did visually identify cervical sinuvertebral nerves and confirmed Cloward's ${ }^{3}$ experimental observations and inferences. Intervertebral disc innervation in the cervical spine is analogous to that in the lumbar spine, with cervical discs receiving innervation posteriorly from the sinuvertebral nerves, laterally from the vertebral nerve, and anteriorly from the sympathetic trunks. ${ }^{5,6}$

Ferlic ${ }^{15}$ first histologically examined innervation of human fetal and adult cervical discs obtained at operation. He found many nerve fibers in the superficial of most peripheral layers of the annulus fibrosus in the fetal specimens, and nerve fibers in two of the 18 sections in the adult specimens. Later, Bogduk et al, ${ }^{5}$ using a cholinesterase stain, showed the presence of nerve fibers and free nerve endings as deeply as the outer third of the annulus fibrosus in human cervical discs obtained at operation. Similar to the report of Bogduk et al, ${ }^{5}$ Mendel et $\mathrm{al}^{6}$ found that free nerve endings and their parent nerve fibers ran throughout the annulus fibrosus of human cervical discs obtained at autopsy. Recently, Yang et $\mathrm{al}^{7}$ found that ingrowth of a large number of free nerve endings into diseased cervical discs obtained from the patients with cervical spondylosis in comparison with the normal discs. Fujimoto et $\mathrm{al}^{4}$ reported that the $\mathrm{C} 5-\mathrm{C} 6$ disc at rats is innervated by $\mathrm{C} 2-\mathrm{C} 8$ dorsal root ganglia (DRG) neurons. Furthermore, this innervation pattern may be a primary contributor to widespread neck pain, because a large proportion of nerve fibers innervating the cervical discs were afferent sensory pain-related nerves that are immunoreactive for calcitonin gene-related peptide (CGRP, a marker for peptide-containing neurons). In lumbar discs such free nerve endings were found to suggest important roles in back pain perception. These studies mentioned above may constitute facts for cervical discs to be an intrinsic source of neck pain.

\section{Degeneration, inflammation, and pain}

A previous study has suggested that the changes of structure and function of cervical disc with degeneration is related to neck pain. ${ }^{16}$ This neck pain is usually accompanied by stiffness of the neck, headache, unilateral or bilateral shoulder pain, nonroot arm pain, ocular and vestibular dysfunction, and pain in the anterior chest wall. ${ }^{9}$ However, the relationship between cervical disc degeneration and clinical neck pain was still unclear. Degeneration of disc is characterized by an elevation in levels of the inflammatory cytokines such as TNF- $\alpha$, IL-1 $\alpha / \beta$, IL-2, IL-4, IL-6, IL-8, IL-10, IL-17, IL-20, and IFN- $\gamma$ secreted by the disc cells themselves, ${ }^{17}$ and these cytokines, in turn, upregulate nerve growth factor (NGF) mRNA expression and the secretion of NGF protein in cultured human disc cells. ${ }^{18}$ Also, cells isolated from human nucleus pulposus in the presence of IL- $1 \beta$ significantly increase NGF DNA expression, whereas treatment with TNF- $\alpha$ was associated with upregulation of substance $P$ (SP, another marker for peptide-containing neurons) in these cells. It was demonstrated that levels of NGF and SP are increased in human painful disc. ${ }^{16}$

These cytokines in degenerative disc promote matrix degradation, chemokine production, and changes in cell phenotype. Release of chemokines from degenerative discs promote infiltration and activation of T- and B-cells, macrophages, and mast cells, further amplifying the inflammatory cascade and release of neurotrophins (NTs), in particular NGF. ${ }^{17,18}$ The onset of the inflammatory condition inside the degenerated disc is a trigger to induce kinds of pathogenic responses, such as cell senescence and apoptosis, as well as nerve and vascular ingrowth. ${ }^{16-18}$

The onset of discogenic pain is characterized by nerve fiber ingrowth into an otherwise aneural tissue. The interplay between inflammatory cytokines and NTs, produced by disc cells and infiltrating immunocytes as well as NT receptors and their modulators, may guide this process. Sensory neurons involved in inflammatory-related pain perception are typically small, NGF-dependent peptide-containing neurons. ${ }^{17,18}$ The increased level of NGF could be retrogradely transported to DRG, in which they could control the expression of some 
neuropeptides like SP and CGRP as well as other molecules related to nociception. In addition, the increased levels of NGF in the disc and the breakdown of the aggrecans will lead to the ingrowth of nociceptive nerve fibers. Therefore, the neurotrophic and neurotropic activities, as well as the sensitizing effects of NGF, make us believe that NGF expressed during disc degeneration contributes to both the nerve ingrowth into the disc and the alterations in gene expression of DRG neurons (Figure 1). The binding of NGF to Trk and p75 expressed by nociceptors initiates complex signal transduction pathways that result in the activation of transcription factors such as NF- $\mathrm{KB}$, which induces the expression of a large number of proinflammatory cytokines. ${ }^{16-20}$

The proinflammatory mediators overexpressed during disc degeneration have a major role in disc matrix degradation, through a direct regulatory action on the expression of both genes associated to fundamental matrix components and degradative matrix proteases. ${ }^{21-23}$ Matrix breakdown in degenerative disc leads to loss of the normal structure and abnormal motion, which can provoke mechanical stimulation. Mechanical stimuli, in certain circumstances such as inflammation, generate an amplified response termed peripheral sensitization through modulation of DRG pain channel activity or by the activity of sympathetic efferents, ${ }^{4}$ which eventually result in pain.

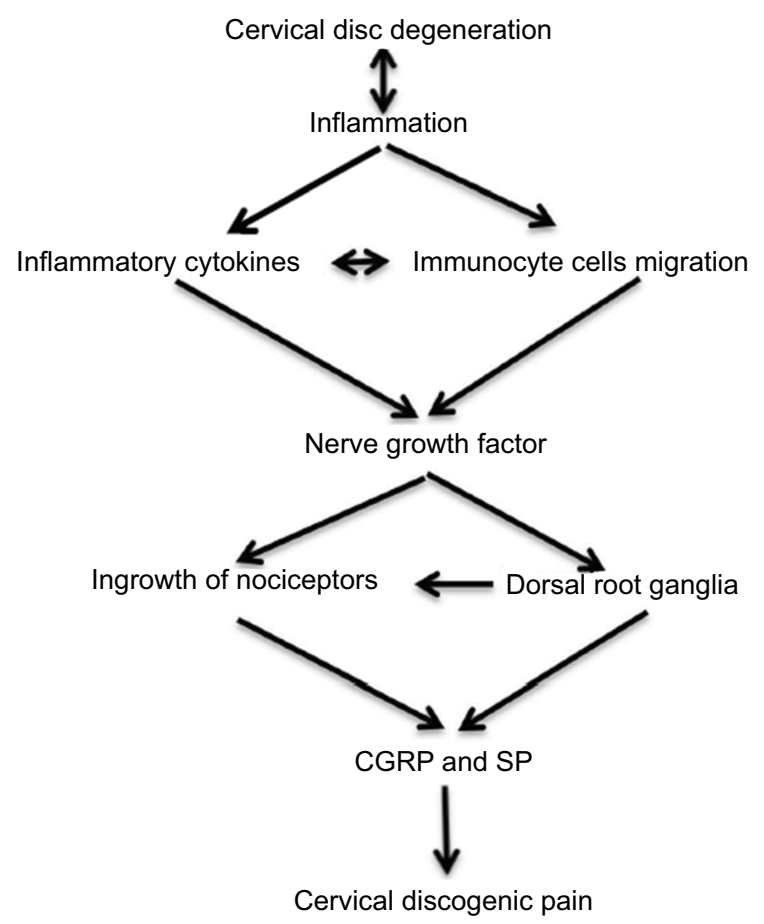

Figure I A schematic diagram of the relationship between cervical disc degeneration, inflammation and discogenic pain.

Abbreviations: CGRP, calcitonin gene-related peptide; SP, substance P.
The intervertebral disc cell can be both a source and a target for NTs. Miyagi et a ${ }^{19}$ reported that disc injury in rats produces persistent increases in NGF, TNF- $\alpha$, and IL-6 in DRG, and that intradiscal application of anti-NGF antibody to lumbar discs suppressed CGRP expression in DRG. Similar to the report of Miyagi et al, ${ }^{19}$ recently, Sainoh et $\mathrm{al}^{20}$ reported that cervical disc injury at rats induced expression of CGRP in the DRG innervating cervical discs, and that intradiscal administration of anti-NGF antibody suppressed CGRP expression in cervical DRG.

\section{Clinical evidence}

Although a number of studies have shown that the degenerative cervical disc is one of the main sources of chronic neck pain; however, some authoritative reviews always stated that there is a lack of consensus regarding causes or treatments for this neck pain alone without disc herniation or cervical radiculopathy. $2,9,10,12$

It is well accepted that anterior cervical surgery is an effective way for cervical radiculopathy or myelopathy caused by cervical disc herniation or spondylosis. The overwhelming clinical evidence ${ }^{24-28}$ reveals that anterior cervical fusion surgery or artificial cervical intervertebral disc replacement can provide rapid relief of symptoms of axial neck pain and radiculopathy or myelopathy simultaneously by removing the source of nerve root or spinal cord compression for the patients with cervical disc herniation or cervical spondylosis. However, the treatment of intractable neck pain by anterior cervical surgery is not an accepted management. This is because the mechanism of postoperative pain relief is not clear. There was an increase in pain-related nerve fibers in both degenerative and herniated cervical discs. Because the contents of the nucleus pulposus are known to directly activate and sensitize nerve fibers, nerve fibers growing into degenerative and herniated discs might provide a potential explanation for these clinical findings. If anterior cervical fusion surgery to reduce axial neck pain is due to the elimination of mechanical instability secondary to bone fusion of the affected segment, artificial cervical intervertebral disc replacement will provide a better explanation for the reduction of this neck pain. The primary goals of cervical disc replacement in the treatment of cervical disc herniation or cervical spondylosis are to preserve motion, allow patients to quickly return to routine activities, and prevent later adjacent level degeneration after removing local disc pathology. Artificial cervical disc replacement can eliminate axial neck pain, further indicating that this neck pain is not from the pathology of other parts, such as the 
posterior facet joints and muscles, but from the pathology of cervical disc itself.

\section{Cervical discography and surgery}

Cervical disc degeneration is common in people without neck pain. Although magnetic resonance imaging (MRI) may identify a degenerative cervical disc, it will not differentiate a disc which is pathologically painful from one which is physiologically aging. The high prevalence of neck pain and disc abnormalities in asymptomatic people provides the conceptual appeal for discography, which is advocated as the only test that connects disease to symptoms, but the procedure remains controversial. ${ }^{2}$ The main criticism of cervical discography, as with any other provocation test, is that disc stimulation may provide pain in normal discs. ${ }^{29}$ However, a normal cervical disc often accept no contrast materials or as little as $0.1-0.2 \mathrm{~mL}$. If strict criteria and technique are maintained, discography can discriminate painful, symptomatic discs from nonpainful, asymptomatic discs. ${ }^{13,14}$ In addition, patients have no pain reproduction response or present only a mild to moderate neck or shoulder pain during injection. MRI can be used as a screening test to demonstrate possible painful levels, whereas discography can be used as an adjunctive confirmatory test. Discography can prevent the levels from unnecessary surgery. The combination of clinical symptoms, MRI, and discography provides the most information for decision-making and can improve the management of cervical discogenic pain. A recent systematic review noted that there is strong evidence for the utility of cervical discography as an intervertebral disc imaging tool and that intradiscal distention can produce pain. ${ }^{29}$

Anterior cervical surgery has not been used routinely for chronic neck pain probably because of a paucity of literature rather than because of poor results. From the numerous clinical studies that have been published, most patients with discogenic neck pain can benefit from anterior cervical fusion surgery. ${ }^{13,14,30-32}$ The overall excellent and good rate is between $70 \%$ and $90 \% .^{13,14,29-32}$ In general, surgeons who reported less favorable outcomes had not performed preoperative discography to determine surgical levels. However, high-quality studies of anterior cervical surgery for cervical discogenic pain without cervical disc herniation or radiculopathy is lacking. Roth ${ }^{32}$ first used analgesic discography to diagnose and locate painful cervical disc in 71 discogenic neck pain patients followed by anterior cervical discectomy and fusion, resulting in a 93\% excellent and good recovery rate. Compared with other studies with a $76 \%$ excellent and good recovery rate used provocative discography, the author concluded that analgesic discography is the most effective test for diagnosis and location of pain-producing disc.

Discogenic neck pain alone without cervical disc herniation or cervical spondylosis accounts for a large proportion of chronic neck pain, and the reported prevalence is between $16 \%$ and $41 \% 0^{2,12,29}$ Although this pain is resolved in most patients through conservative therapy, there are patients who continue to have refractory neck pain. Some people are even told that they have nothing to do, and they must learn to live with it. For these patients, it is necessary to actively seek for more effective treatment. In this case, anterior cervical fusion or artificial cervical disc replacement may become the last option for surgeons. However, preoperative cervical discography can guarantee a better surgical outcome.

\section{Disclosure}

The authors report no conflicts of interest in this work.

\section{References}

1. Fejer R, Kyvik KO, Hartvigsen J. The prevalence of neck pain in the world population: a systematic critical review of the literature. Eur Spine J. 2006;15(6):834-848.

2. Manchikanti L, Boswell MV, et alASIPP-IPM, et al. Comprehensive evidence-based guidelines for interventional techniques in the management of chronic spinal pain. Pain Physician. 2009;12(4):699-802.

3. Cloward RB, Discography C. Technique, indications and use in the diagnosis of ruptured cervical discs. Am J Roentgenol Radium Ther Nucl Med. 1958;79:563-574.

4. Fujimoto K, Miyagi M, Ishikawa T, et al. Sensory and autonomic innervation of the cervical intervertebral disc in rats: the pathomechanics of chronic discogenic neck pain. Spine. 2012;37(16):1357-1362.

5. Bogduk N, Windsor M, Inglis A. The innervation of the cervical intervertebral discs. Spine. 1988;13(1):2-8.

6. Mendel T, Wink CS, Zimny ML. Neural elements in human cervical intervertebral discs. Spine. 1992;17(2):132-135.

7. Yang L, Yang C, Pang X, et al. Mechanoreceptors in Diseased Cervical Intervertebral Disc and Vertigo. Spine. 2017;42(8):540-546.

8. Binder AI. Cervical spondylosis and neck pain. BMJ. 2007;334(7592):527-531.

9. Cohen SP, Hooten WM. Advances in the diagnosis and management of neck pain. BMJ. 2017;358:j3221.

10. Evans G. Identifying and treating the causes of neck pain. Med Clin North Am. 2014;98(3):645-661.

11. Carragee EJ, Hurwitz EL, Cheng I, et al. Treatment of neck pain: injections and surgical interventions: results of the Bone and Joint Decade 2000-2010 Task Force on Neck Pain and Its Associated Disorders. J Manipulative Physiol Ther. 2009;32(2 Suppl):S176-S193.

12. Yin W, Bogduk N. The nature of neck pain in a private pain clinic in the United States. Pain Med. 2008;9(2):196-203.

13. Whitecloud TS, Seago RA, Syndrome Cdiscogenic. Cervical discogenic syndrome. Results of operative intervention in patients with positive discography. Spine. 1987;12(4):313-316.

14. Siebenrock KA, Aebi M. Cervical discography in discogenic pain syndrome and its predictive value for cervical fusion. Arch Orthop Trauma Surg. 1994;113(4):199-203.

15. Ferlic DC. The nerve supply of the cervical intervertebral disc in man. Bull Johns Hopkins Hosp. 1963;113:347-351. 
16. Garcia-Cosamalon J, del Valle ME, Calavia MG, et al. Intervertebral disc, sensory nerves and neurotrophins: who is who in discogenic pain? J Anat. 2010;217:1-15.

17. Navone SE, Marfia G, Giannoni A, et al. Inflammatory mediators and signalling pathways controlling intervertebral disc degeneration. Histol Histopathol. 2017;32(6):523-542.

18. Risbud MV, Shapiro IM. Role of cytokines in intervertebral disc degeneration: pain and disc content. Nat Rev Rheumatol. 2014;10(1):44-56.

19. Miyagi $M$, Ishikawa $T$, Orita $S$, et al. Disk injury in rats produces persistent increases in pain-related neuropeptides in dorsal root ganglia and spinal cord glia but only transient increases in inflammatory mediators: pathomechanism of chronic diskogenic low back pain. Spine. 2011;36(26):2260-2266

20. Sainoh T, Sakuma Y, Miyagi M, et al. Efficacy of anti-nerve growth factor therapy for discogenic neck pain in rats. Spine. 2014;39(13):E757-E762.

21. Wang SS, Zhang W, Zhang YQ, et al. IL-17A enhances ADAMTS-7 expression through regulation of TNF- $\alpha$ in human nucleus pulposus cells. J Mol Histol. 2015;46(6):475-483.

22. Wang W-J, Yu X-H, Wang C, et al. MMPs and ADAMTSs in intervertebral disc degeneration. Clinica Chimica Acta. 2015;448:238-246.

23. Lai Y, Bai X, Zhao Y, et al. ADAMTS-7 forms a positive feedback loop with TNF- $\alpha$ in the pathogenesis of osteoarthritis. Ann Rheum Dis. 2014;73(8):1575-1584.

24. Sasso RC, Smucker JD, Hacker RJ, Heller JG. Artificial disc versus fusion: a prospective, randomized study with 2-year follow-up on 99 patients. Spine. 2007;32(26):2933-2940.
25. Gornet MF, Burkus JK, Shaffrey ME, Argires PJ, Nian H, Harrell FE. Cervical disc arthroplasty with PRESTIGE LP disc versus anterior cervical discectomy and fusion: a prospective, multicenter investigational device exemption study. J Neurosurg Spine. 2015;2015(31): 558-573.

26. Cepoiu-Martin M, Faris P, Lorenzetti D, Prefontaine E, Noseworthy T, Sutherland L. Artificial cervical disc arthroplasty: a systematic review. Spine. 2011;36(25):E1623-E1633.

27. Gao Y, Liu M, Li T, Huang F, Tang T, Xiang Z. A meta-analysis comparing the results of cervical disc arthroplasty with anterior cervical discectomy and fusion (ACDF) for the treatment of symptomatic cervical disc disease. J Bone Joint Surg Am. 2013;95(6):555-561.

28. Zhang Y, Liang C, Tao Y, et al. Cervical total disc replacement is superior to anterior cervical decompression and fusion: a meta-analysis of prospective randomized controlled trials. PLoS One. 2015;10(3): e0117826.

29. Onyewu O, Manchikanti L, Falco FJ, et al. An update of the appraisal of the accuracy and utility of cervical discography in chronic neck pain. Pain Physician. 2012;15(6):E777-E806.

30. Simmons EH, Segil CM. An evaluation of discography in the localization of symptomatic levels in discogenic disease of the spine. Clin Orthop Relat Res. 1975;108(108):57-69.

31. Palit M, Schofferman J, Goldthwaite N, et al. Anterior discectomy and fusion for the management of neck pain. Spine. 1999;24(21):2224-2228.

32. Roth DA. Cervical analgesic discography. A new test for the definitive diagnosis of the painful-disk syndrome. JAMA. 1976;235(16):1713-1714.
Journal of Pain Research

\section{Publish your work in this journal}

The Journal of Pain Research is an international, peer reviewed, open access, online journal that welcomes laboratory and clinical findings in the fields of pain research and the prevention and management of pain. Original research, reviews, symposium reports, hypothesis formation and commentaries are all considered for publication.

\section{Dovepress}

The manuscript management system is completely online and includes a very quick and fair peer-review system, which is all easy to use. Visit http://www.dovepress.com/testimonials.php to read real quotes from published authors. 